\title{
Irish Wolfhound
}

National Cancer Institute

\section{Source}

National Cancer Institute. Irish Wolfhound. NCI Thesaurus. Code C53916.

A massive, muscular dog, the Irish Wolfhound is one of the tallest breeds in the world.

This gentle giant can reach the The Irish Wolfhound is a massive, muscular dog, and is one of the tallest breeds in the world. It can reach the size of a small pony and has a rough, shaggy coat and wiry bushy eyebrows. Colors include gray, brindle, red, black or white. Gray is the most common color. The paws are large and round, with arched toes and strong, curved nails. Height: 28-35 inches (71-90 cm.) Weight: 90-150 pounds (40-69 kg.) 